\title{
Physical Activity and Health-Related Internet Usage during Covid-19 Pandemic in Indonesian Society
}

\author{
Aktivitas Fisik dan Penggunaan Internet Terkait Informasi \\ Kesehatan selama Pandemi Covid-19 pada Masyarakat \\ Indonesia
}

\author{
DELA PUTRI AMALIA*, NABILA DHIYA ULHAQ, KANIA DEWI RAFA, FARADIBA \\ Departement of Biology, Faculty of Mathematics and Natural Sciences IPB University, Jl. Agatis Kampus IPB, \\ Bogor 16680
}

Diterima 11 September 2021/Disetujui 26 December 2021

\begin{abstract}
Physical activity is defined as any bodily movement produced by skeletal muscles. Several factors can influence a person's physical activity levels, one of them is work from home (WFH) policy caused by Covid-19. This policy could reduce a person's physical activity. To maintain health during the Covid-19 pandemic, most people access the internet to find health-related information. However, there is no information about the physical activity level and the relationship between physical activity and health-related internet usage during the Covid-19 pandemic in Indonesian society. This study asked 83 participants from 32 cities in Indonesia to fill the questionnaire related to their activity using the International Physical Activity Questionnaire (IPAQ) and the purpose of internet usage. Most of the respondents had moderate activity levels. Females were more active than males during the Covid-19 pandemic. A higher intensity of working from home negatively correlated with a physical activity score, however, it was not statistically significant. People who used the internet to search for a healthy diet and healthy life information were more physically active than those who did not. Thus, we assumed that people who used the internet to search for a healthy diet and healthy life information have high awareness about their health.
\end{abstract}

Key words: Indonesia, internet usage, IPAQ, MET, physical activity

\section{INTRODUCTION}

Physical activity is defined as any bodily movement produced by skeletal muscles that result in energy expenditure (McKinney et al. 2016). People with high physical activity tend to have higher life satisfaction and better health (An et al. 2020). Several factors can influence a person's physical activity levels, such as age, sex, and environmental conditions (Caspersen et al. 1999; Suryadinata et al. 2020; Teran-Escobar et al. 2021). One environmental condition affecting someone's physical activity is the Covid-19 pandemic (Kaur et al. 2020). Covid-19 is an infectious disease that can spread through person-to-person interactions via direct contact or droplets spread by coughing or sneezing from an infected person to a non-infected person (Rothan and Byrareddy 2020). To reduce the number of transmissions of Covid-19, the government establish a Work from Home (WFH) policy (Mohler et al. 2020).

*Penulis korespondensi:

E-mail: delaputriamalia24@gmail.com
Work From Home (WFH) policy could reduce physical activity due to the lack of outdoor exercise (Fuzeki et al. 2020). To cover the lack of physical activity and maintain health during the Covid-19 pandemic, most people access the internet to find health-related information such as a healthy lifestyle (Parial et al. 2021). In addition, the previous study in UK and Australia showed that the Covid-19 pandemic has led to increases in population-level interest in physical activity (Ding et al. 2020). However, there is no information about the physical activity level and the relationship between physical activity and health-related internet usage during the Covid-19 pandemic in Indonesian society.

Thus, this study aimed to examine Indonesian people's physical activity and find out the relationship between physical activity and health-related internet usage during the Covid-19 pandemic.

\section{MATERIAL AND METHOD}

Respondents. The total number of respondents used in this study were 83 individuals consisted of 
20 males and 63 females with age ranged between 15 to 49 years old (Table 1 ).

Procedures. A national cross-sectional study was performed in September 2020. The questionnaire was put in the Google Form media, consists of four sections; the first section is the introductory page, informing respondents about the study's purpose, the researcher's contact address, and informed consent, the second section asked about demographic information, the third section asked about the respondent's purpose of using the internet, and the last section asked about physical activity using the International Physical Activity Questionnaire (IPAQ). Respondent's answers obtained from the questionnaire are confidential and only used for study purposes.

International Physical Activity Questionnaire (IPAQ). International Physical Activity Questionnaire (IPAQ) is a personal report related to physical activity in the past week (Ainsworth et al. 2006). The questionnaire assesses physical activity undertaken across a comprehensive set of domains, including leisure time, domestic, gardening (yard) activities, work-related, and transport-related activity calculated in minutes per day or days per week. In each domain, respondents reported the frequency and duration of different types of activity: vigorous (i.e. heavy lifting, performing intense aerobic exercises, using bike or treadmill); moderate (i.e. sweeping, mopping, gardening); walking activities, as well as the average time, spent sitting on a weekday, including sitting at work (Maugeri et al. 2020). IPAQ is consist of two versions, the short version and the long version. In this study, we used the long version of IPAQ because the questionnaire ask details of specific task of activities. The example of the question is "How much time did you usually spend on one of those days doing vigorous physical activities?".

IPAQ classified total activity into three different groups; low, moderate, and high based on Metabolic Equivalent Task (MET) level. Metabolic Equivalent Task (MET-min/wk) is a value to quantify the energy cost of individual activities. A higher MET-min/wk score of individuals equals to the energy expenditure that they spend.

Statistical Analysis. The statistical analyses were conducted using the statistical software RStudio version 1.4.1103 for descriptive statistics and correlation analysis (R Core Team 2013). Spearman's rank correlation coefficients were calculated to determine the correlation between physical activity with the intensity of working from home. In order to examined the difference between independents variables, we used Kruskal-Wallis test (Van Hecke 2011).

\section{RESULTS}

Demographic of Respondents. The total number of respondents that participated in this study were 83 participants (20 males and 63 females). The age of
Table 1. Demographic data of the respondents

\begin{tabular}{|c|c|c|c|}
\hline & Variable & $\mathrm{N}^{*}$ & Percentage (\%) \\
\hline \multirow[t]{3}{*}{ Sex } & Male & 20 & 24.10 \\
\hline & Female & 63 & 75.90 \\
\hline & Total & 83 & 100.00 \\
\hline \multirow[t]{33}{*}{ Cities } & Bandarlampung & 1 & 1.20 \\
\hline & Bandung & 2 & 2.41 \\
\hline & Bayua & 1 & 1.20 \\
\hline & Bekasi & 2 & 2.41 \\
\hline & Bengkulu & 1 & 1.20 \\
\hline & Bogor & 10 & 12.05 \\
\hline & Boyolali & 1 & 1.20 \\
\hline & Bukittinggi & 2 & 2.41 \\
\hline & Denpasar & 1 & 1.20 \\
\hline & Depok & 2 & 2.41 \\
\hline & Jakarta & 8 & 9.64 \\
\hline & Jatinangor & 1 & 1.20 \\
\hline & Kubu Raya & 2 & 2.41 \\
\hline & Malang & 1 & 1.20 \\
\hline & Manokwari & 1 & 1.20 \\
\hline & Minahasa & 1 & 1.20 \\
\hline & Padang & 1 & 1.20 \\
\hline & Pagaralam & 1 & 1.20 \\
\hline & Palembang & 1 & 1.20 \\
\hline & Palu & 1 & 1.20 \\
\hline & Pekalongan & 1 & 1.20 \\
\hline & Pematangsiantar & 2 & 2.41 \\
\hline & Pontianak & 25 & 30.12 \\
\hline & Samarinda & 1 & 1.20 \\
\hline & Sambas & 1 & 1.20 \\
\hline & Siak & 1 & 1.20 \\
\hline & Situbondo & 1 & 1.20 \\
\hline & Sleman & 2 & 2.41 \\
\hline & Sukabumi & 1 & 1.20 \\
\hline & Sumedang & 1 & 1.20 \\
\hline & Tangerang & 5 & 6.02 \\
\hline & Tasikmalaya & 1 & 1.20 \\
\hline & Total & 83 & 100.00 \\
\hline
\end{tabular}

$\mathrm{N}^{*}$ : Number of individual

respondents ranged between 15 to 49 years old. The mean age of the respondents was $21.89+6.33$ years old $\left(\mathrm{M}_{\text {males }}=21.35\right.$ years, s.d. $=3.34$ years; $\mathrm{M}_{\text {females }}$ $=22.06$ years, s.d. $=7.03$ years). Demographic data of respondents were shown in Table 1.

Physical Activity of Respondents. Most of the respondents $(75.90 \%)$ in the study were categorized as individuals with a moderate physical activity, followed by 17 respondents $(20.48 \%)$ categorized as individuals with high physical activity, and 3 respondents $(3.61 \%)$ categorized as individuals with low physical activity as shown in Table 2 .

Sex Difference in MET Score. This result showed that female had higher MET-min/wk scores than male $($ Female $=23598.47+23106.70$, Male $=$ $17065.80+19321.14)$, indicating that female were more physically active than male. However, this result was not significantly different (Figure 1).

Correlation between Intensity of Working from Home with MET. Intensity of working from home had a negative correlation with MET-min/wk score, although it was not statistically significant (Spearman cor.test, Rho $=0.1, \mathrm{p}$-value $=2.2 \mathrm{e}-10$ ). The result 
showed that the higher intensity of working from home, the lower the MET-min/wk score as shown in Figure 2.

Respondents Internet Usages. This result showed that there was a significant difference between people who used and did not use the internet as the source of healthy diet information (Kruskal-wallis, $\mathrm{p}$-value $\left.=0.0319^{*}\right)$. People who used the internet to search healthy diet information had a higher physical activity levels that those who did not (Table 3 ).

\section{DISCUSSION}

There was a similarity between the present study with a study by Jalloun and Surrati (2020), which

Table 2. Category of respondent's physical activity

\begin{tabular}{lrc}
\hline Category of physical activity & $\mathrm{N}^{*}$ & Percentage (\%) \\
\hline Low & 3 & 3.61 \\
Moderate & 63 & 75.90 \\
High & 17 & 20.48 \\
Total & 83 & 100.00 \\
\hline N*. Number of individual & &
\end{tabular}

showed that moderate activity was higher than other types of activities (vigorous, walking, and sitting). This result might happen because most vigorous physical activities such as running, cycling, and fast swimming were usually done outside. However, during the Covid-19 pandemic, these facilities were difficult to access. Thus, people prefer to do

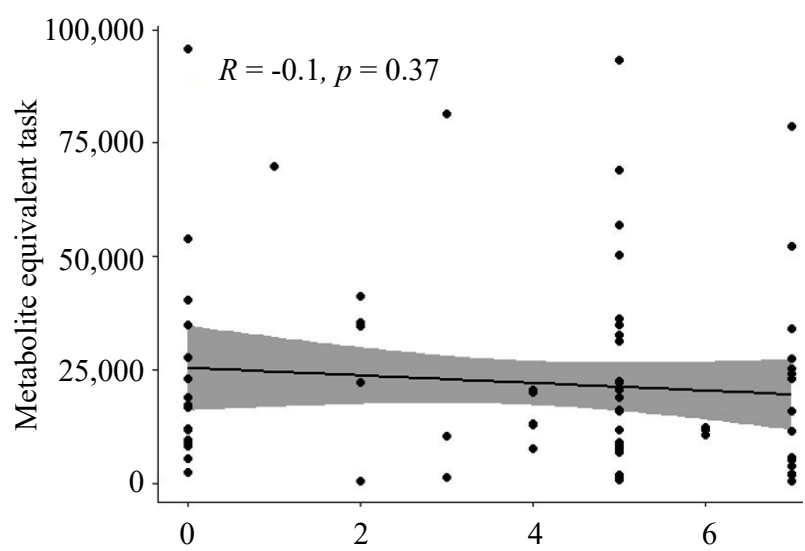

Figure 1. Correlation between intensity of working from home with metabolite equivalent task

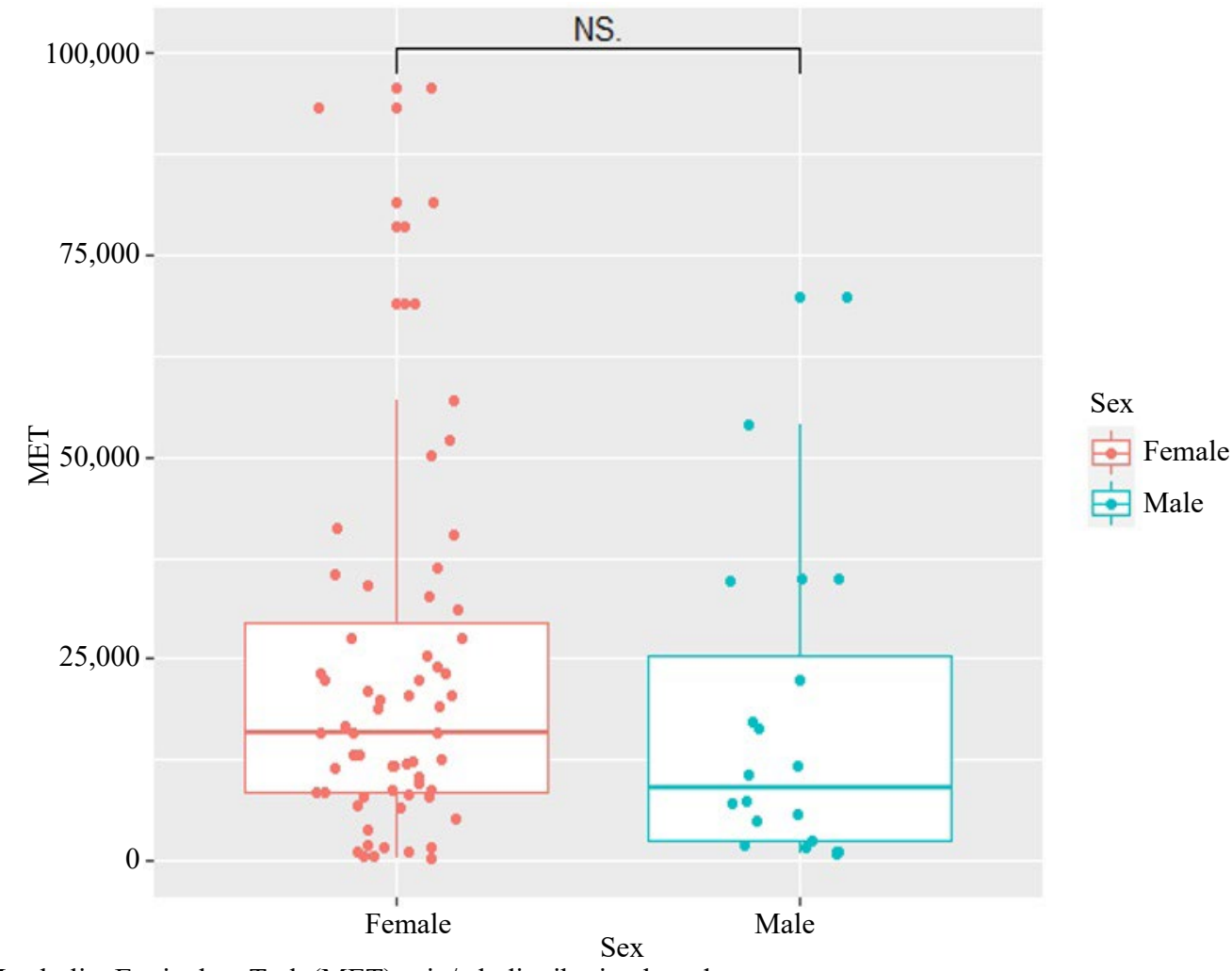

Figure 2. Metabolite Equivalent Task (MET)-min/wk distribution based on sex

Table 3. Average of MET-min/wk with the purpose of using the internet

\begin{tabular}{|c|c|c|c|c|c|}
\hline & \multicolumn{2}{|r|}{ Yes } & \multicolumn{2}{|r|}{ No } & \multirow{2}{*}{$\begin{array}{l}\mathrm{p} \text {-value between } \\
\text { yes or no }\end{array}$} \\
\hline & Average & Standard deviation & Average & Standard deviation & \\
\hline age on healthy diet & $23,648.15$ & $23,011.44$ & $8,672.93$ & $6,971.54$ & $0.0319^{*}$ \\
\hline Internet usage on healthy life & $23,206.94$ & $23,071.22$ & $10,937.33$ & $7,236.96$ & 0.1673 \\
\hline
\end{tabular}

*statistically significant 
physical activities with lower intensity levels or moderate activities such as housework (Maugeri et al. 2020).

Several factors could influence physical activity; one of them is sex. In our study, females showed a higher average metabolic equivalent task (MET) $\mathrm{min} / \mathrm{wk}$ score than male (Female $=23598.80+$ 23106.70, Male $=17065.80+19321.14)$. This finding differed from previous studies that showed males were more physically active than females (Ozdol et al. 2012; Maugeri et al. 2020). This result is possibly explained by the higher amount of housework physical activities (e.g., sweeping and mopping) found in females than males during the Covid-19 pandemic (Maugeri et al. 2020). In addition, males prefer to do sports outside and/or in public places such as soccer fields, gyms, fitness clubs (Li et al. 2017). Therefore, it could lower their physical activity during the Covid-19 pandemic.

The present study showed that the higher the intensity of working from home, the lower the physical activity levels. This result was in line with Blanco et al. (2020) and Rathonyi et al. (2021), which showed that working from home was associated with increased sedentary behavior (McDowell et al. 2020; Hallman et al. 2021). Hence, it led to a decrease in MET levels. These behaviors harmed people's healthy habits and could be at risk of being physically inactive (Thorp et al. 2012).

This study also sought to find out the purpose of using the internet during the Covid-19 pandemic. The result showed that people who used the internet to search for healthy life and healthy diet information had higher physical activity levels than those who did not use the internet to search for it. This study predicted that those who used the internet to search for healthy life information were concerned about their health and would eventually adopt a healthy diet. Therefore, we assumed that people who used the internet to search for a healthy diet and healthy life information have high awareness about their health.

In conclusion, during quarantine in Indonesia, people tend to do moderate activity compared to other types of activity. Females had a higher physical activity level than males during the Covid-19 pandemic. People who Work from Home (WFH) tend to have lower MET scores even though the result was not statistically significant. People who used the internet to search for a healthy diet and healthy life information were more physically active than those who did not. This study assumed that they were aware that people who used the internet to search for a healthy diet and healthy life information have high awareness about their health.

\section{ACKNOWLEDGEMENTS}

The authors would like to thank Dr. Kanthi Arum Widayati for her technical support during experiment and valuable discussion. The authors would also like to thank all of the respondents that participated in this research.

\section{REFERENCES}

Ainsworth BE, Macera CA, Jones DA, Reis JP, Addy CL, Bowles HR, Kohl HW. 2006. Comparison of the 2001 BRFSS and the IPAQ physical activity questionnaires. $\mathrm{Med} S \mathrm{Sci}$ Sports Exerc 38:1584-1592.

An HY, Chen W, Wang CW, Yang HF, Huang WT, Fan SY. 2020. The relationships between physical activity and life satisfaction and happiness among young, middle-aged, and older adults. Int J Environ Res Public Health 17:1-10.

Blanco CR, Almagro JR, Zafra MDO, Fernandez MLP, Laguna MDCP, MartinezAH. 2020. Physical activity and sedentary lifestyle in university students: changes during confinement due to the COVID-19 pandemic. International Journal of Environmental Research and Public Health 17:1-13.

Caspersen CJ, Pereira MA, Curran KM. 1999. Changes in physical activity patterns in the United States, by sex and crosssectional age. Official Journal of the American College of Sports Medicine 32:1601-1609.

Ding D, Cruz BP, Green MA, Bauman AE. 2020. Is the Covid-19 lockdown nudging people to be more active: a big data analysis. $B M J$ 54:1-6.

Fuzeki E, Groneberg DA, Banzer W. 2020. Physical activity during COVID-19 induced lockdown: recommendations. J Occup Med Toxicol 12:1-5.

Hallman DM, Januario LB, Mathiassen SE, Heiden M, Svensson S, Bergstrom G. 2021. Working from home during the Covid-19 outbreak in Sweden: effects on 24-h time-use in office workers. BMC Public Health 21:1-10.

Jalloun RA, Surrati AM. 2020. Physical activity pattern among female college student at Taibah University. International Journal of Nutrition 10:137-143.

Kaur H, Singh T, Arya YK, Mittal S. 2020. Physical fitness and exercise during the Covid-19 pandemic: a qualitative enquiry. Front Physchol 11:1-10.

Li W, Procter-Gray E, Churchill L, Crouter SE, Kane K, Cheng J, Rui F, Tian J, Franklin PD, Ockene JK, Gurwitz J. 2017. Gender and age differences in levels, types and locations of physical activity among older adults living in car-dependent neighborhoods. J Frailty Aging 6:129-135.

Maugeri G, Castrogiovanni P, Battaglia G, Pippi R, D'Agata V, Palma A, Rosa MD, Musumeci G. 2020. The impact of physical activity on psychological health during COVID-19 pandemic in Italy. Heliyon 6:1-8.

McDowell CP, Herring MP, Lansing J, Brower C, Meyer JD. 2020. Working from home and job loss due to the Covid-10 pandemic are associated with greater time in sedentary behaviors. Front Public Health 8:1-5.

McKinney J, Lithwick DJ, Morrison BN, Nazzari H, Isserow SH, Heilbron B, Krahn AD. 2016. The health benefits of physical activity and cardiorespiratory fitness. $B c$ Medical Journal 58(3):131-137.

Mohler G, Bertozzi AL, Carter J, Short MB, Sledge D, Tita GE, Uchida CD, Bratingham PJ. 2020. Impact of social distancing during COVID-19 pandemic on crime in Los Angeles and Indianapolis. Journal of Criminal Justice 69:1-7.

Ozdol Y, Ozer MK, Pinar S, Cetin E. 2012. Investigation of physical activity levels by gender and residential areas: a case study on students in Akdeniz University. ProcediaSocial and Behavioral Sciences 46:1581-1586. 
Parial, Llyod L, Xu, Xinyi, Kor, Patrick, Cheung, Teris, Wong, Eliza. 2021. Online health information seeking during Covid-19 pandemic and its association with psychological well-being in Chinese older adults. Asian Journal of Gerontology and Geriatrics 16:58.

R Core Team. 2013. R: A language and environment for statistical computing. Vienna(AT): R Foundation for Statistical Computing.

Rathonyi G, Kosa K, Bacs Z, Rathonyi-Odor K, Fuzesi I, Lengyel P, Baba EB. 2021. Changes in workers' physical activity and sedentary behaviour during the Covid-19 pandemic. Sustainability 13:1-25.

Rothan HA, Byrareddy SN. 2020. The epidemiology and pathogenesis of coronavirus disease (COVID-19) outbreak. Journal of Autoimmunity 109:1-4.

Suryadinata RV, Wirjatmadi B, Adriani M, Lorensia A. 2020. Effect of age and weight on physical activity. J Public Health Res 9:187-190.
Teran-Escobar C, Forestier C, Ginoux C, Isoard-Gautheur S, Sarrazin P, Clavel A, Chalabaev A. 2021. Individual, sociodemographic, and environmental factors related to physical activity during the spring 2020 Covid-19 lockdown. Front Pyschol 12:1-13.

Thorp AA, Healy GN, Winkler E, Clark BK, Gardiner PA, Owen N, Dunstan DW. 2012. Prolonged sedentary time and physical activity in workplace and non-work contexts: a cross-sectional study of office, customer service and call centre employees. Int J Behav Nutr Phys Act 9:1-9.

Van Hecke T. 2011. Power study of anova versus Kruskal-Wallis test. Journal of Statistic and Management Systems 15:241247. 